\title{
The age of enlightenment: evolving opportunities in brain research through optical manipulation of neuronal activity
}

\author{
Jason Jerome and Detlef H. Heck* \\ Department of Anatomy and Neurobiology, University of Tennessee Health Science Center, Memphis, TN, USA
}

\section{Edited by:}

Raphael Pinaud, University of Oklahoma Health Sciences Center, USA

\section{Reviewed by:}

Daniela Tropea, Trinity College Dublin, Ireland

Edward B. Brown, University of Rochester, USA

\section{*Correspondence:}

Detlef H. Heck, Department of

Anatomy and Neurobiology,

University of Tennessee Health

Science Center, 855 Monroe Avenue,

Suite 515, Memphis, TN 38163, USA.

e-mail:dheck@uthsc.edu
Optical manipulation of neuronal activity has rapidly developed into the most powerful and widely used approach to study mechanisms related to neuronal connectivity over a range of scales. Since the early use of single site uncaging to map network connectivity, rapid technological development of light modulation techniques has added important new options, such as fast scanning photostimulation, massively parallel control of light stimuli, holographic uncaging, and two-photon stimulation techniques. Exciting new developments in optogenetics complement neurotransmitter uncaging techniques by providing cell-type specificity and in vivo usability, providing optical access to the neural substrates of behavior. Here we review the rapid evolution of methods for the optical manipulation of neuronal activity, emphasizing crucial recent developments.

Keywords: caged compounds, light-sensitive ion channels, optical stimulation, optogenetics, digital light processing, spatiotemporal activity, synchrony

\section{INTRODUCTION}

An understanding of the physiological mechanisms involved in conscious and subconscious processes in the nervous system requires tools to manipulate and observe the activity of living neurons at spatial and temporal scales relevant to the investigative problem. The complexity and scale of neuronal interconnections drive the demand for faster and more spatially precise physiology research tools. Regardless of the neurophysiology model system, amplified electrical recordings and chemical observations and manipulations are tried and true techniques that have seen widespread use since the dawn of neuroscience. The most common technique for manipulating synaptic inputs, electrical stimulation, has severe disadvantages over newly available alternatives. One is the number and flexibility of stimulation sites. Even with multielectrode arrays, the number of sites is typically less than 100. Furthermore, there is no flexibility in the spatial arrangement or the size of stimulation sites as electrodes are arranged on a fixed grid and the location of sites is determined by the placement and orientation of the grid. Another disadvantage of electrical stimulation is its poor anatomical specificity as it mostly activates fibers of passage and not somata and dendrites (Nowak and Bullier, 1998) and results in antidromic activation of neurons. This is particularly problematic in regions of the brain like the neocortex, where a high density of axons originating from multiple brain regions passes through every cortical layer. More recently, optical techniques for the bidirectional control of neuronal excitation have overcome many technical barriers, including exceptionally high spatial and temporal precision, and cell-type specificity. The following review provides a brief history of optical stimulation techniques and discusses the experimental strengths and weaknesses of a variety of different photostimulation approaches. The strengths and weaknesses of the different light modulation techniques are summarized in Table $\mathbf{1}$ with a comparison of caged neurotransmitters and light-sensitive ion channels in Table 2.

\section{CAGED NEUROTRANSMITTERS}

The development of caged compounds has had a profound effect on the biological sciences. A caged compound is formed by chemically altering a normally physiologically active molecule to include a covalently bonded functional group, often called a "protecting group" or simply a "cage." In order qualify as a caged compound, the protecting group must have several properties. First, the cage, when chemically bonded, must render the caged molecule biologically inactive while minimizing other physiological consequences. Second, the cage must be quickly and specifically removed by photolytic cleavage. In most cases, the action spectrum of photolytic cleavage for caged compounds is in the UV spectrum. UV light, therefore, can control the active concentration of the caged molecule in a temporally (microsecond) and spatially (micrometer) precise manner. Finally, the photoreleased caged must be itself biologically inert such that photolytic activation of the caged compound results only in the action of the target molecule, and not the protecting group.

The utility of caged compounds in biology was first demonstrated with caged ATP (Kaplan et al., 1978). Neuroscience, though, has arguably gained the most from the development of caged compounds through the availability of caged neurotransmitters. In the vertebrate brain, neurotransmitters are released in complex spatial and temporal patterns at synaptic connection between neurons. With approximately $10^{11}$ neurons and $10^{14}$ synapses in the human brain, the spatiotemporal patterns of neurotransmitter release and postsynaptic activation are exceptionally complex. Caged neurotransmitters allow investigators to study the dynamics of neurotransmitter release. Photoliable amino acid neurotransmitters were first synthesized in 1990 (Wilcox et al., 1990) and then 


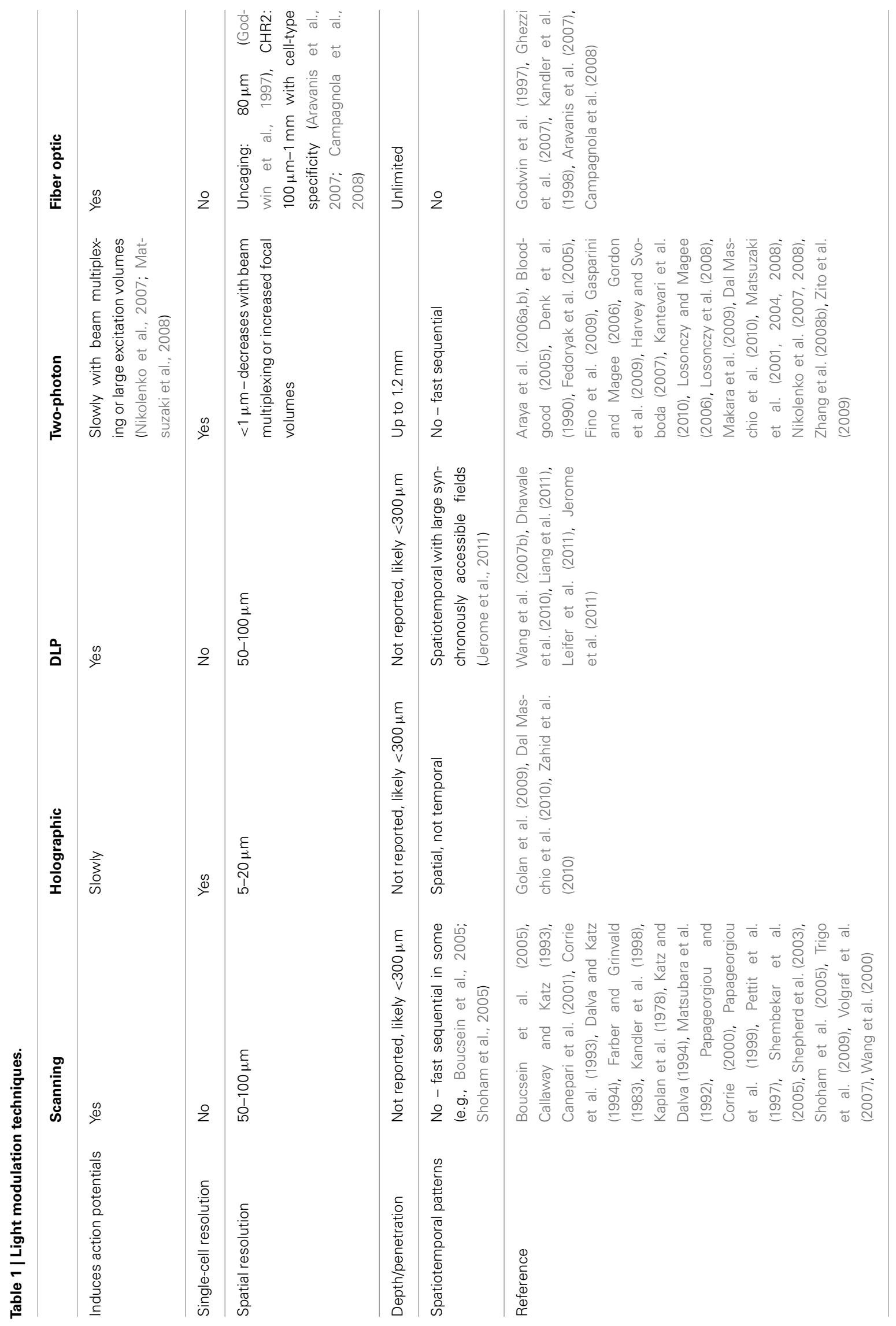


Table 2 | Photostimulation substrates.

\begin{tabular}{|c|c|c|}
\hline & Caged neurotransmitters & Light-sensitive ion channels \\
\hline Cell-type specific/genetically targetable & No & Yes \\
\hline Bidirectional & Yes - demonstrated with 2P only (Kantevari et al., 2010) & $\begin{array}{l}\text { Yes - with expression of multiple channels and } \\
\text { multicolor photostimulation (Han and Boyden, 2007) }\end{array}$ \\
\hline Activates axons of passage & No & Ectopic: yes - Modified endogenous: no \\
\hline In vivo applicability & No & Yes \\
\hline Reference & $\begin{array}{l}\text { Araya et al. (2006a,b), Bloodgood (2005), Boucsein } \\
\text { et al. (2005), Callaway and Katz (1993), Canepari et al. } \\
\text { (2001), Corrie et al. (1993), Dalva et al. (1997), Far- } \\
\text { ber and Grinvald (1983), Fedoryak et al. (2005), Fino } \\
\text { et al. (2009), Furuta et al. (1999), Gasparini and Magee } \\
\text { (2006), Ghezzi etal. (2007, 2008), Godwin etal. (1997), } \\
\text { Golan et al. (2009), Gordon et al. (2009), Harvey and } \\
\text { Svoboda (2007), Jerome et al. (2011), Kandler et al. } \\
\text { (1998), Kantevari et al. (2010), Katz and Dalva (1994), } \\
\text { Liang et al. (2011), Losonczy and Magee (2006), Loson- } \\
\text { czy et al. (2008), Maier et al.. (2007), Makara et al. } \\
\text { (2009), Matsubara et al. (1992), Matsuzaki et al. (2001, } \\
\text { 2004, 2008), Nikolenko et al. (2007), Papageorgiou } \\
\text { and Corrie (2000), Papageorgiou et al. (1999), Pettit } \\
\text { et al. (1997), Richardson et al. (2009), Shembekar et al. } \\
\text { (2005), Shepherd et al. (2003), Shoham et al. (2005), } \\
\text { Suga et al. (1998), Trigo et al. (2009), Volgraf et al. }\end{array}$ & $\begin{array}{l}\text { Abbott et al. (2009a,b), Adamantidis et al. (2007), } \\
\text { Alilain et al. (2008), Aravanis et al. (2007), Arenkiel } \\
\text { et al. (2007), Atasoy et al. (2008), Banghart et al. } \\
\text { (2004, 2006), Bi et al. (2006), Blaustein et al. (2000), } \\
\text { Boyden et al. (2005), Cardin et al. (2010), Carter } \\
\text { et al. (2009), Chambers and Kramer (2008), Dhawale } \\
\text { et al. (2010), Douglass et al. (2008), Fortin et al. } \\
\text { (2011), Gorostiza and Isacoff (2007), Govorunova } \\
\text { et al. (2011), Han and Boyden (2007), Gunaydin et al. } \\
\text { (2010), Hira et al. (2009), Huber et al. (2008), Ishizuka } \\
\text { et al. (2006), Lewis et al. (2009), Li et al. (2005), } \\
\text { Liewald et al. (2008), Lima and Miesenböck (2005), } \\
\text { Lin et al. (2009), Nagel (2002), Nagel et al. (2003, } \\
\text { 2005), Petreanu et al. (2007), Schroll et al. (2006), } \\
\text { Szobota et al. (2007), Tønnesen et al. (2009), Volgraf } \\
\text { et al. (2006), Wang et al. (2007a), Zemelman et al. } \\
\text { (2002), Zhang et al. (2008a,b), Mohanty et al. (2008) }\end{array}$ \\
\hline
\end{tabular}

(2007), Wang et al. (2000), Wilcox et al. (1990), Zahid

et al. (2010), Zhang et al. (2008b)

first use in elucidating the kinetics of the nicotinic acetylcholine receptor (Matsubara et al., 1992).

Glutamate is the primary excitatory neurotransmitter in the brain and is consequently the most commonly used caged neurotransmitter today. Virtually every neuron type in the vertebrate and invertebrate nervous system is activated by glutamate making the use of this caged neurotransmitter universally effective. Several different caged variations are in use with each having unique properties (discussed later). The first use of caged glutamate was to study the glutamatergic activation of the giant squid synapse (Corrie et al., 1993) and later for the mapping of functional circuitry in the acute brain slice preparation (Callaway and Katz, 1993). Before the availability of caged neurotransmitters, a light-based mapping system was proposed (Farber and Grinvald, 1983), however, this system induced action potentials by irreversibly damaging or killing the targeted cell and also stimulated axons of passage, making mapping of connections in axon-dense brain regions impossible.

Caged glutamate is currently most widely used in studies of synaptic physiology, synaptic plasticity, and functional circuitry in both normal and diseased states. The utility of any photostimulation system depends critically on the method of light modulation, which determines the spatiotemporal complexity of stimulus patterns. Various methods of photostimulation are discussed below, including the recent developments of ectopic or reengineered light-sensitive ion channels. Caged calcium has also contributed immensely to neuroscience as reviewed by Ellis-Davies (2008). Since caged calcium is most instrumental in studies of single-cell physiology, we have omitted further discussion of its use here and have focused this review on photostimulation techniques related to the investigation of circuits, networks, and integrative properties of neurons.

\section{UNCAGING WITH ULTRAVIOLET LIGHT}

Currently, the most common scheme for photostimulation involves an objective-focused ultraviolet beam for scanning uncaging patterns. Due to a lack of commercialization of this method, multiple variations exist with no two systems being exactly identical, so this review will survey the various components of these systems in generalities.

The selection of an excitation light source is flexible and contributes greatly to the variability of system configurations. In the earliest systems and in many still used today, a xenon flash lamp directly coupled to the epifluorescence port is used to generate the photolyzing UV radiation (Callaway and Katz, 1993). More commonly though, lasers (Dalva and Katz, 1994; Katz and Dalva, 1994) are used because of their high output power, narrow emission spectrum, and other technical advantages such as fiber optic coupling and alignment simplicity. However, even the choice of laser varies greatly, with success reported 
with pulsed frequency-tripled Nd:YVO (Shepherd et al., 2003), continuous wave argon lasers (Dalva and Katz, 1994; Katz and Dalva, 1994), or excimer dye lasers (Maier et al., 2007), all of which are set up to emit in the near UV $(315-380 \mathrm{~nm})$, the wavelength band with the highest uncaging yield. Uncaging success has also been achieved with $405 \mathrm{~nm}$ visible-light (Trigo et al., 2009), which offers slightly decreased phototoxicity and tissue scattering at the cost of lower photolytic efficiency.

The position of the photostimulation target is modulated in a few different ways. With stationary scopes, a low power $(5-10 \times)$ objective provides a large field of view while the beam is steered into position by a pair of galvanometric mirrors and coupled to the microscope's epifluorescence port. With this method, the precise focal depth is difficult to control due to different targets in the field of view having different path lengths, so a low NA objective to generate a cylindrical beam is required.

The other common method expands the beam to fill the back aperture of a high NA, high magnification objective, generating a conical uncaging beam. The position of photorelease in the slice is modulated by a double- or triple-axis translating stage, moving the target of photostimulation relative to the fixed position of the photolysis site. Alternatively, fiber coupling of the UV source to the epifluorescence port allows the stage to be fixed while the stage-mounted microscope is moved to new targets. While this scheme is mechanically more complex and results in slower scans, systems of this type use light more efficiently, as explained in the next paragraph.

The rate at which caged compounds are released from their cage is an important parameter in photostimulation experiments as it determines the speed at which responses can be induced (i.e., the temporal precision of action potential induction). This rate is dependent on the flux density (i.e., the number of photolytic photons in a given volume) at the target stimulation site. In conical beams, the focal point of the beam has a higher flux density than any other point in the beam while in a cylindrical beam, the flux density is the same throughout the beam. Consequently, when using a cylindrical beam, greater total power is required to match the flux density at the focal point of a conical beam. With the higher total-power in cylindrical beams, the uncaging medium above the target site is subject to the same flux density and thus same high rate of caged compound release, while in conical beams, the rate is focused and optimal at the object plane exclusively. As a result, the practical lifetime of recirculated caged glutamate solution is slightly reduced in galvanometric mirror systems, which also require more-expensive higher-power light sources to achieve the same photolysis rate at the intended target.

A few unique variations of UV photostimulation systems are in current use, each with its own advantages. Introduction of galvanometric-mirror-modulated excitation light from beneath the recording chamber has eliminated the problem of excessive bath solution uncaging as the majority of the excitation light is dissipated within the slice before passing through the bath solution (Boucsein et al., 2005). This system also allows very fast scans over a large field of view. Very fast scans have also been realized with an acousto-optic deflector used as a beam position modulator (as opposed to galvanometric scanners; Shoham et al.,
2005). This system also allows for the study of synaptic integration of pseudo-synchronous input, as beam position updates can occur on the scale of $50 \mu$ s per spot, although over a smaller area $(170 \mu \mathrm{m} \times 170 \mu \mathrm{m})$. While faster and technically less difficult to implement, the light throughput of acousto-optic systems is lower than galvanic mirror systems as the acousto-optic medium absorbs a significant amount of light.

The practical spatial limitation for uncaging applications is the radius of glutamate release around a focused uncaging site. Under normal circumstances, the theoretical diffraction-limited optical resolution and practical uncaging resolution (i.e., uncaging radius) are different by several orders of magnitude. In thick, inhomogeneous media like brain slices, the uncaging resolution is limited by light scatter and diffusion of uncaged glutamate. At these ultraviolet wavelengths, the theoretically calculated Rayleigh criterion $\left(r=1.22 \lambda_{\mathrm{UV}} / 2 \mathrm{NA}_{\mathrm{obj}}\right)$ predicts an optical resolution of $<1 \mu \mathrm{m}$ while the minimum resolvable distance between uncaging spots is typically around $50-100 \mu \mathrm{m}$. Thus in most standard UV uncaging setups, target sites have to be spaced by $50 \mu \mathrm{m}$ or more to activate non-overlapping populations of neurons.

While most UV photostimulation systems do not achieve single-cell resolution, they do allow investigators to resolve laminar organization of synaptic input to the postsynaptic cell. Resolution may be increased by recently described holographic uncaging systems (Golan et al., 2009; Dal Maschio et al., 2010). However, this elegant but technically complex and expensive technique may have as many disadvantages as advantages. First, excitation spots cannot be chosen arbitrarily but must be generated by holographic reconstruction of fluorescent images with computationally complex algorithms, requiring genetically tagged or dye-filled neurons to stimulate. Second, the light modulator, a liquid-crystal spatiallight-modulator (SLM), has a relatively slow refresh rate (approximately $60 \mathrm{~Hz}$ ), limiting its ability to present sequential spatial patterns and therefore spatiotemporally complex stimuli. Finally, while a holographic system has demonstrated the ability to induce action potentials in single-cells (Zahid et al., 2010), the speed and temporal precision of excitation by laser scanning systems is much greater. However, the potential for mapping synaptic connections at a single-cell spatial precision is a significant advantage and holographic photostimulation may also prove instrumental in studies of dendritic spatial integration by taking advantage of the improved resolution of direct-dendritic stimulation. Resolution has also been improved with a system utilizing the principles of total-internal-reflection (TIRF) microscopy in which an evanescent wave of UV light was used to activate caged calcium near the surface of coverslip-cultured cells (Suga et al., 1998). However, this system probably has low utility in an acute slice preparation in which most of the viable presynaptic cells are outside the reach of an evanescent wave.

A large number of caged glutamate variants have been synthesized, including a reversibly caged glutamate (Volgraf et al., 2007) and a double-caged glutamate for slightly improved UV resolution at the expense of a higher-power requirement (Dalva et al., 1997; Pettit et al., 1997; Wang et al., 2000). A visible-light-sensitive caged glutamate was first described in 2005 (DECM-glutamate; Shembekar et al., 2005). The decreased cost of visible-light sources is an obvious advantage and makes photostimulation systems attainable 
for more labs, but visible-light-sensitive caged neurotransmitters are also advantageous because visible-light scatters significantly less in tissue, improving the effective resolution of photostimulation. RuBi-glutamate, another visible-light-sensitive caged glutamate, also has less GABA-antagonistic activity and has a greater quantum yield, allowing it to be used in lower concentrations while reducing the antagonistic effects on inhibitory networks (Fino et al., 2009). However, the sensitivity of these caging groups to ambient room light reduces the stability in solution, requiring dark rooms and shielding of light-emitting equipment. On the other hand, the exceptional stability, the capability of being frozen, thawed and reused, the relatively low cost, and the wide availability of MNI-glutamate makes it the most commonly used caged glutamate in both UV and two-photon photostimulation experiments.

Multiple uncaging systems have been described with fiber optic light delivery (Godwin et al., 1997; Kandler et al., 1998; Ghezzi et al., 2007, 2008). These systems have the advantage that the photolytic light does not have to be focused through a microscope objective, making them appropriate for multiple types of thicker preparations, including in vivo applications where the depth of stimulation is limited only by the length of the fiber. However, they suffer from the facts that they are highly invasive, spatially inflexible, and that positioning of fibers can be very time consuming as compared to scanning systems. Additionally, the in vivo loading and replenishing of caged neurotransmitters deeper than the surface of the brain to practical concentrations is difficult if not impossible, thus fiber optic photostimulation in vivo has only be accomplished when combined with optogenetics (discussed later; Aravanis et al., 2007; Campagnola et al., 2008).

\section{MULTIPHOTON UNCAGING}

Not long after Einstein (1905) elucidated the mechanism of the photoelectric effect, in which quanta of light cause electron energystate transitions resulting in measurable electric current, GöppertMayer (1931) described a theoretical excitation scheme in which simultaneous absorption of two or more low-energy photons results in electron-state transitions. Proof of this theory, though, would have to wait for the advent of the laser, due to the necessary high flux density of excitatory photons. This was finally achieved in cesium vapor nearly three decades later (Abella, 1962) and applied to fluorescence excitation shortly thereafter (Peticolas et al., 1963).

Denk et al. (1990) applied two-photon excitation to fluorescence microscopy. Several advantages exist for two-photon excitation fluorescence microscopy (2P) compared to confocal or other fluorescence microscopy techniques. In $2 \mathrm{P}$, the excitation volume is effectively confined in $3 \mathrm{D}$ at the focal point of the objective, where the flux density is at a maximum and two-photon excitation events become several orders of magnitude more probable. In addition to matching the $3 \mathrm{D}$ imaging capabilities of confocal fluorescence microscopy, the infrared excitation wavelengths in $2 \mathrm{P}$ are significantly less phototoxic and damaging, allowing the observation of living tissue. The elimination of the confocal aperture combined with the relatively long $2 \mathrm{P}$ excitation wavelengths that are less susceptible to scattering, allow fluorescence 3D imaging in vivo at depths up to $1 \mathrm{~mm}$. Finally, 2P provides unmatched resolution of $3 \mathrm{D}$ photolysis of biologically relevant caged molecules, first demonstrated with photolysis of DMNPE-caged ATP in a bioluminescence assay (Denk et al., 1990).

While Denk et al. (1990) speculated that improved modulation of biologically relevant caged compounds would benefit from $2 \mathrm{P}$, many caged compounds, including most of the caged neurotransmitters, were not suitable for $2 \mathrm{P}$ photolysis due to their low propensity for $2 \mathrm{P}$ photoactivation, a measure formally called two-photon cross section with units named the Goeppert-Mayer. The first such caged neurotransmitter to be efficiently released by two-photon photolysis (BHC-glutamate) was described in 1999, and was used to generate a $3 \mathrm{D}$, neuronal sensitivity map to glutamate (Furuta et al., 1999). Since then, multiple variations of glutamate with a two-photon-sensitive cage have emerged with each variation developed for the purpose of improving stability, improving caged inertness, increasing quantum yield, widening the action spectrum, or improving two-photon cross section including MNI-glutamate (Papageorgiou et al., 1999; Papageorgiou and Corrie, 2000; Canepari et al., 2001; Matsuzaki et al., 2001), MDNI-glutamate (Fedoryak et al., 2005), and RuBi-glutamate (Fino et al., 2009). RuBi-glutamate, mentioned earlier, in addition to being visible-light-sensitive, is also two-photon-sensitive at wavelengths longer than those used for MNI-glutamate, allowing for better penetration and resolution in thicker preparations. The peak output power of the commonly used tuned Ti-Sapphire infrared lasers occurs at wavelengths closer to those used for $2 \mathrm{P}$ RuBi-glutamate uncaging $(800 \mathrm{~nm})$ than those used for $2 \mathrm{P}$ MNIglutamate uncaging $(725 \mathrm{~nm})$. Overall, the improved quantum yield and light source efficiency allows RuBi-glutamate to be used at concentrations at least five times lower than MNI-glutamate. This, in combination with its lower GABA-antagonistic activity, makes it an effective tool for the study of inhibitory network activity and connectivity (Fino et al., 2009).

With $2 \mathrm{P}$ photostimulation, the near-infrared (NIR) photodamage threshold and limited practical concentration of bath-applied caged glutamate limits the rate of caged glutamate release at any one spot. Generally, a higher photolysis yield requires longer dwell times. While this is not a problem for the study of sub-threshold synaptic integration, action potential initiation, and therefore presynaptic stimulation, is severely limited with two-photon systems. In one non-standard setup, a diffractive optical element was used to split the uncaging beam into several closely spaced beamlets (Nikolenko et al., 2007). This system was capable of eliciting action potentials with $30 \mu \mathrm{m}$ resolution and $5 \mathrm{~ms}$ dwell times in some cells, with 30-50 ms dwell times being typical (supplementary material for Nikolenko et al., 2007). However, due to the beam multiplexing and lack of adequate controls, it is unclear whether this system is capable of single-cell specificity. Regardless, it is possible to generate neuronal connectivity maps by sequentially scanning targeted neurons with resolution and specificity better than that offered by traditional ultraviolet photostimulation systems. Similar results were found by increasing the two-photon excitation volume by reducing the effective numerical aperture of the objective (Matsuzaki et al., 2008). In this case, it was shown that resolution, while greater than UV systems, generally stimulated multiple cells at each target.

Additional disadvantages of two-photon photostimulation are a result of the gap in current availability of NIR laser power and 
the required flux density of NIR photons for efficient photolysis of even the most easily photolyzed caged glutamate varieties. The recent description of a SLM based scanless 2P microscope illustrated this particular weakness, in which increasing the number of synchronous targets decreased the response amplitude to glutamate uncaging, presumably due to a redistribution of available light power and low throughput efficiency of SLM-based systems. Even with a single-cell being targeted, the initiation of action potentials required very long dwell times $(100 \mathrm{~ms}$ in the author's example case; Nikolenko et al., 2008).

With these limitations, it is not possible to induce synchronous action potentials from two or more spatially separated presynaptic neurons. Therefore, investigating the integration of coincident input or the consequences of neuronal synchrony in large-scale circuits is beyond the capabilities of $2 \mathrm{P}$ glutamate uncaging. However, the ability to target individual spines and achieve patterned, pseudo-synchronous activation of multiple targeted spines in a limited field of view has been achieved with $2 \mathrm{P}$ uncaging and has been the method of choice for numerous investigations (Matsuzaki et al., 2001, 2004; Bloodgood, 2005; Araya et al., 2006a,b; Gasparini and Magee, 2006; Losonczy and Magee, 2006; Harvey and Svoboda, 2007; Losonczy et al., 2008; Zhang et al., 2008b; Gordon et al., 2009; Makara et al., 2009; Richardson et al., 2009; Zito et al., 2009).

\section{LIGHT-SENSITIVE ION CHANNELS AND RECEPTORS}

Photostimulation schemes utilizing bath-applied caged neurotransmitters are useful for many types of investigations, including synaptic physiology and laminar organization of many structures. However, in many brain regions, a single structure may contain a dense mixture of multiple neuron subtypes, which are activated indiscriminately by photostimulation via neurotransmitter uncaging. To overcome this limitation, many investigators have developed methods of targeting individual cell-types with a combination of genetic and optical techniques. These optogenetic techniques alter the intrinsic photoexcitability of functionally distinct cell groups, allowing for a different approach to the investigation of neural circuits. These techniques are briefly reviewed here.

The first realization of this capability required the ectopic expression of three phototransducing genes from the retina of Drosophila in mammalian neurons. Using this technique, intrinsic light sensitivity was demonstrated in oocytes and cultured hippocampal neurons (Zemelman et al., 2002). Even though this phototransduction cascade is relatively fast and involves fewer gene products than the vertebrate phototransduction cascade, directly gated light-sensitive ion channels from phototaxic algae have now been introduced to mammalian cells. Channelrhodopsin- 1 is a fast activating/inactivating light-gated proton channel (Nagel, 2002) and Channelrhodopsin-2 (Chr2) is a slow activating/inactivating non-selective cation channel (Nagel et al., 2003). Functional Chr2 was introduced with lentiviral infection into cultured mammalian neurons twice independently in 2005 (Boyden et al., 2005; Li et al., 2005), followed by the generation of several lines of transgenic mice expressing Chr2 in a subset of functional distinct neurons in the mouse under the control of the Thyl promoter (Wang et al., 2007a). A good illustration of this selective expression is found in the Thy1-Chr2/YFP line 18 mouse, in which expression in the neocortex is limited to pyramidal cells in layer V. Therefore, photostimulation of cortex selectively activates layer $\mathrm{V}$ pyramidal cells, while others remain quiescent. This allows investigators to selectively map inputs from layer $\mathrm{V}$ pyramidal cells onto other neurons without confounding the input from other cell-types within cortex. Additionally, the use of expensive and depletable caged neurotransmitters is made unnecessary by the fact that light sensitivity is intrinsic to the genetically defined neuronal subset.

While the mosaic expression of Thyl promoted genes appears partially random and dependent on transgene copy number and insertion location (Feng et al., 2000), many other groups have since used other genetic and molecular tools to express Chr2 in alternative subsets of neurons in anatomically restricted regions. For example, the selection and implementation of an alternative promoter in a lentiviral transfection vector has allowed Chr2 to be specifically expressed in hypocretin-expressing neurons under the control of the prepro-hypocretin promoter (Adamantidis et al., 2007). An additional advantage of lentiviral transfection of lightsensitive ion channels is that the region of transfection can be limited anatomically due to the limited spread of the viral vector. The Cre-recombinase-dependent viral-transfection protocol has also been described in detail (Atasoy et al., 2008) and limits expression to anatomically restricted sites in cre transgenic mice. A simpler approach of restricting $\mathrm{Chr} 2$ to cre-lines is also possible with a Ch2 transgenic available from Jaxmice (stock number 012567) The transgene in these mice contains a loxP-flanked STOP cassette ahead of the coding region that prevents downstream transcription of the Chr2 gene (Madisen et al., 2010). When crossed with a transgenic mouse expressing Cre-recombinase in a promoter-specified subset of cells, the STOP cassette is excised, and CHR2 is expressed in all genetically defined target cells across the entire brain.

Since not all neuronal subpopulations contain a known unique promoter, developmentally timed in utero electroporation may restrict spatiotemporal expression to populations which are genetically indiscriminate (Saito and Nakatsuji, 2001; Matsui et al., 2011). For example, the functionally and anatomically distinct subtypes of cortical pyramidal neurons do not have unique promoters and differentiate from common neural progenitors at different points in development to form layers with distinct geometries and functional roles. Pyramidal neurons have been targeted via developmentally timed electroporation of neuronal progenitors (Petreanu et al., 2007) and Chr2 was selectively expressed in layer $2 / 3$ but not in layer 5 . In contrast, a mouse with a CAMKII- $\alpha$ promoted Chr2 transgene would express the channel in glutamatergic neurons throughout the brain (Benson et al., 1992).

Another unique feature of transgenic light-sensitive-ionchannel-expressing neurons is that they can be activated in vivo and thus allow the investigation of the neuronal substrates of behavior at an unprecedented level of specificity, including the contribution of neuronal subpopulations to appetitive and aversive learning in Drosophila (Schroll et al., 2006), avoidance, body elongation, and contraction in C. elegans (Nagel et al., 2005; Liewald et al., 2008), in ovo movement initiation of chick embryos (Li et al., 2005), targeted motor output and functional mapping by optogenetic stimulation of rodent motor cortex (Aravanis et al., 2007; Hira et al., 2009) olfactory processing in mouse (Arenkiel et al., 2007), sleep homeostasis in mouse (Adamantidis et al., 2007; 
Carter et al., 2009), somatosensory learning in mouse (Huber et al., 2008) breathing (Abbott et al., 2009a) and sympathetic nerve activity (Abbott et al., 2009b) in rat, and swimming and escape behavior in zebrafish (Douglass et al., 2008; Zhu et al., 2009). This capability also presents the potential for therapeutic uses of Chr2 in many disease states, including the rescue of breathing after spinal cord injury (Alilain et al., 2008) vision restoration (Bi et al., 2006) and suppression of epileptiform activity (Tønnesen et al., 2009). A full description of the protocol for in vivo targeted optogenetic control of neuronal activity and behavior can be found in Cardin et al. (2010).

While Chr2-assisted circuit mapping has many advantages when compared to neurotransmitter uncaging, there are several glaring disadvantages. Early in the development of optogenetic tools, Chr2 activation had slower kinetics than glutamatergic activation, limiting the precise temporal control of action potential output. Specifically, inactivation of unmutated Chr2 is about 10 times slower than its activation, resulting in plateau depolarizations and multiple spikes in response to a single light pulse. Chr2-driven spike trains cannot exceed $40 \mathrm{~Hz}$, therefore, precise control of neural activity into the gamma band of neural activity is not possible (Ishizuka et al., 2006; Gunaydin et al., 2010). Reengineered variants of Chr2 with improved kinetics have overcome this obstacle (Lin et al., 2009; Gunaydin et al., 2010) and one of these mutations has been incorporated into the cre-dependent line of channelrhodopsin-2 mice (Jaxmice stock number 012567).

Another disadvantage is due the subcellular distribution of Chr2 in transgenic animals and most cell culture preparations. $\mathrm{Chr} 2$ is indiscriminately and uniformly distributed in the plasma membrane including axons, while glutamate receptors are limited to the dendrites and cell bodes of neurons. Therefore, blue light activation of Chr 2 activates both cell bodies and axons of passage, making it impossible to precisely determine from where the synaptic connection originates. This is also true of cut axon terminals in slice preparations, which may still be activated and release neurotransmitter, giving potentially confounding results in attempts to elucidate microcircuitry. This too, though, has been partially overcome by adding a myosin-dependent targeting sequence to the transgene, restricting Chr2 expression to dendrites (Lewis et al., 2009), although at the time of this review's writing, a transgenic mouse with this modification is not available. For the investigation of circuits with short range targets, such as in the neocortex, where high densities of axons originating from multiple brain regions pass through every cortical layer, this issue is particularly problematic.

In light of these limitations, it is more appropriate to classify the roles of intrinsically light-sensitive ion channels and uncagingbased photostimulation systems as complementary rather than competing technologies. In fact, these tools have been combined for optical induction of plasticity at single synapses (Zhang et al., 2008b). Also, bidirectional control of neuronal output is possible with the introduction of a yellow-sensitive chloride-pump (Han and Boyden, 2007). Additionally, multiple genetically distinct subsets of neurons can be differentially activated with redsensitive excitatory channels (Zhang et al., 2008a; Govorunova et al., 2011). Conversely, bimodal control of membrane potential by neurotransmitter uncaging is only possible on two-photon systems, and has only been demonstrated very recently (Kantevari et al., 2010).

An alternative to ectopic expression of transgenic ion channels is the modification of endogenous ion channels to be photosensitive. The first success with this concept was the description of a nicotinic acetylcholine receptor with a covalently bonded photoisomerizable tethered agonist (Lester et al., 1980). This achievement was remarkable in that it was accomplished without the availability of site-directed-mutagenesis. It was not until more than two decades later that another such channel emerged. A reengineered shaker potassium channel with a cysteine substituted for Glu422 allows for the conjugation of a light-switchable azobenzene tether attached to a pore blocking antagonist similar to TEA (Blaustein et al., 2000; Banghart et al., 2004, 2006). A similar design was implemented for the realization of a light-gated glutamate receptor (Volgraf et al., 2006), which has since been shown to allow optical control of action potential input in vitro and in vivo (Szobota et al., 2007). As with Chr2, neural substrates of behavior can be investigated with these channels, as has been demonstrated with escape behavior in zebrafish (Szobota et al., 2007) and jumping, wing beating, and flight in Drosophila with a photoswitchable purino receptor (Lima and Miesenböck, 2005). While the popularity of these reengineered channels suffers from the fact that they involve additional, potentially toxic steps to implement (conjugation of tethered ligands), they may still be useful for some applications (Gorostiza and Isacoff, 2007; Chambers and Kramer, 2008). In fact, Kv3.1-, Kv7.2-, and SK2-containing potassium currents, which do not have specific pharmacological blockers, have been tethered to a quaternary ammonia potassium channel blocker with a photoisomerizable azobenzene (Fortin et al., 2011). These modified $\mathrm{K}+$ channels can be specifically and reversibly manipulated, a feat not possible with pharmacology alone.

\section{PARALLEL PHOTOSTIMULATION TECHNIQUES}

A major drawback of most existing photostimulation techniques is that they are limited to sequential stimulation. Activity in the brain however, consists of complex spatiotemporal patterns which can only be emulated using techniques that allow massively parallel control of a large number of photostimulation sites. There is substantial experimental and theoretical evidence supporting a role of synchronous spiking activity for information processing in the brain. For example, synchronized spikes have been shown to represent essential features of visual (Kreiter and Singer, 1996; Dan et al., 1998) auditory (deCharms and Merzenich, 1996; Huetz et al., 2009) and gustatory (Gutierrez et al., 2010) stimuli and to encode motor events (Vaadia et al., 1995; Gutierrez et al., 2010) and also represent cognitive functions such as attention (Riehle, 1997; Steinmetz et al., 2000). Currently, most of our knowledge about the generation and propagation of synchronous spike activity in the neocortex stems from theoretical studies (Salinas and Sejnowski, 2001; Kumar et al., 2010). Technical challenges have hindered direct and thorough experimental investigations of neuronal synchrony in biological networks. As a result, there is a large gap between theoretical predictions and our neurophysiological understanding of the mechanisms underlying neocortical synchronous spiking activity. 
Photostimulation systems based on digital light processing (DLP, Texas Instruments) technology allow for thousands of parallel photostimulation beams. DLP systems are built around a digital micro mirror device (DMD), an array of several hundred thousand microscopic mirrors, with each mirror corresponding to a potential photostimulation site. Each mirror can be independently positioned to reflect light in one of two directions. With the mirror in the "on" position, light is reflected through a projection lens, making the corresponding site (pixel) appear bright. Light reflected from a mirror in the "off" position is directed toward a heat sink, causing the site on the projection plane to remain dark (Single-Panel DLP Projection System Optics, 2005). While typically used in multimedia applications with frame rates between 5 and $240 \mathrm{~Hz}$, the array of DMD mirrors can be switched at rates of tens of kilohertz with the appropriate software and hardware controllers. DMDs thus provide high-speed parallel control of hundreds of thousands of light beams, one for each micromirror, affording the opportunity to control complex spatiotemporal activity patterns, including synchrony, over a large range of scales to emulate neuronal interactions as they occur in vivo.

The first use of DLP technology in neuroscience provided spatiotemporal control of neuronal activity in cultured rat hippocampal neurons expressing light-activated glutamate receptors at a rate of $10 \mathrm{~Hz}$ (Wang et al., 2007a). Activation of Chr2-expressing neurons with DLP photostimulation has also been used to generate glomerular input maps to mitral-tufted cells in olfactory bulb (Dhawale et al., 2010) and to manipulate the movement of unrestrained C. elegans expressing Chr2 (Leifer et al., 2011). A recently described Ultraviolet DLP photostimulation system has been used to investigate dendritic integration of sub-threshold stimuli by uncaging glutamate at distal dendritic branch points (Liang et al., 2011). However, with limited subcellular resolution,

\section{REFERENCES}

Abbott, S. B. G., Stornetta, R. L., Fortuna, M. G., Depuy, S. D., West, G. H., Harris, T. E., and Guyenet, P. G. (2009a). Photostimulation of retrotrapezoid nucleus Phox $2 b$-expressing neurons in vivo produces long-lasting activation of breathing in rats. J. Neurosci. 29, 5806.

Abbott, S. B. G., Stornetta, R. L., Socolovsky, C. S., West, G. H., and Guyenet, P. G. (2009b). Photostimulation of channelrhodopsin2 expressing ventrolateral medullary neurons increases sympathetic nerve activity and blood pressure in rats. $J$. Physiol. (Lond.) 587, 5613-5631.

Abella, I. (1962). Optical doublephoton absorption in cesium vapor. Phys. Rev. Lett. 9, 453-455.

Adamantidis, A. R., Zhang, F., Aravanis, A. M., Deisseroth, K., and de Lecea, L. (2007). Neural substrates of awakening probed with optogenetic control of hypocretin neurons. Nature 450, 420-424.

Alilain, W. J., Li, X., Horn, K. P., Dhingra, R., Dick, T. E., Herlitze, S., and Silver, J. (2008). Light-induced rescue of breathing after spinal cord injury. J. Neurosci. 28, 11862.

Aravanis, A. M., Wang, L.-P., Zhang, F., Meltzer, L. A., Mogri, M. Z., Schneider, M. B., and Deisseroth, K. (2007). An optical neural interface: in vivo control of rodent motor cortex with integrated fiberoptic and optogenetic technology. J. Neural Eng. 4, S143-S156.

Araya, R., Eisenthal, K. B., and Yuste, R. (2006a). Dendritic spines linearize the summation of excitatory potentials. Proc. Natl. Acad. Sci. U.S.A. 103, 18799.

Araya, R., Jiang, J., Eisenthal, K. B., and Yuste, R. (2006b). The spine neck filters membrane potentials. Proc. Natl. Acad. Sci. U.S.A. 103, 17961-17966.

Arenkiel, B. R., Peca, J., Davison, I. G., Feliciano, C., Deisseroth, K., Augustine, G. J., Ehlers, M. D., and Feng, G. (2007). In vivo light-induced activation of neural circuitry in transgenic mice expressing channelrhodopsin2. Neuron 54, 205-218.

Atasoy, D., Aponte, Y., Su, H. H., and Sternson, S. M. (2008). A FLEX switch targets channelrhodopsin-2

UV photostimulation mostly activates extrasynaptic receptors, which may have implications in dendritic processing.

A unique strength of DLP-modulated light is that multiple sites can be activated with perfect synchrony or arbitrarily specified delays at a very high rate to investigate the processing of synchronous activity by individual neurons or neural networks (Jerome et al., 2011). This system, which requires the high light output of a high-power frequency-tripled ND:YAG laser, is capable of inducing action potentials with dwell times as low as $3 \mathrm{~ms}$. With the massively parallel capacity of light modulation, the synchrony of large numbers of anatomically distributed neurons can be manipulated. The control of action potential firing at high temporal resolution in multiple presynaptic neurons now allows for the investigation of important questions related to temporal synaptic integration of spatially distributed inputs and the generation and propagation of synchronous population activity in neural networks.

\section{CONCLUSION}

Light-based stimulation has greatly enhanced the available tools for investigating the spatially complex connections between neurons in the central nervous system. Mechanical, spatial, and other technical limitations of electrode and electrophoresis-based stimulation have been overcome with light-based techniques, in which the flexibility and resolution of chemical stimulation depends solely on the method of light modulation. Quick and efficient mapping of inputs across large brain regions is now common, along with investigations of strength, size, and density of convergent inputs in axon-dense regions such as the neocortex. The recent introduction of parallel photostimulation provides new vistas for the investigation of complex spatiotemporal activity patterns, including synchronous population activity, and their role in normal and pathological brain function.

to multiple cell types for imaging and long-range circuit mapping. $J$. Neurosci. 28, 7025.

Banghart, M., Borges, K., Isacoff, E., Trauner, D., and Kramer, R. H. (2004). Light-activated ion channels for remote control of neuronal firing. Nat. Neurosci. 7, 1381-1386.

Banghart, M. R., Volgraf, M., and Trauner, D. (2006). Engineering light-gated ion channels. Biochemistry 45, 15129-15141.

Benson, D. L., Isackson, P. J., Gall, C. M., and Jones, E. G. (1992). Contrasting patterns in the localization of glutamic acid decarboxylase and $\mathrm{Ca} 2+/$ calmodulin protein kinase gene expression in the rat central nervous system. Neuroscience 46, 825-849.

Bi, A., Cui, J., Ma, Y. P., Olshevskaya, E., Pu, M., Dizhoor, A. M., and Pan, Z. H. (2006). Ectopic expression of a microbial-type rhodopsin restores visual responses in mice with photoreceptor degeneration. Neuron 50, 23-33.

Blaustein, R. O., Cole, P. A., Williams, C., and Miller, C. (2000). Tethered blockers as molecular "tape measures" for a voltage-gated $\mathrm{K}+$ channel. Nat. Struct. Biol. 7, 309-311.

Bloodgood, B. L. (2005). Neuronal activity regulates diffusion across the neck of dendritic spines. Science 310, 866-869.

Boucsein, C., Nawrot, M., Rotter, S., Aertsen, A., and Heck, D. (2005). Controlling synaptic input patterns in vitro by dynamic photo stimulation. J. Neurophysiol. 94, 2948-2958.

Boyden, E. S., Zhang, F., Bamberg, E., Nagel, G., and Deisseroth, K. (2005). Millisecond-timescale, genetically targeted optical control of neural activity. Nat. Neurosci. 8, 1263-1268.

Callaway, E. M., and Katz, L. C. (1993). Photostimulation using caged glutamate reveals functional circuitry in living brain slices. Proc. Natl. Acad. Sci. U.S.A. 90, 7661.

Campagnola, L., Wang, H., and Zylka, M. J. (2008). Fiber-coupled lightemitting diode for localized photostimulation of neurons expressing channelrhodopsin-2. J. Neurosci. Methods 169, 27-33. 
Canepari, M., Nelson, L., Papageorgiou, G., Corrie, J. E., and Ogden, D. (2001). Photochemical and pharmacological evaluation of 7-nitroindolinyl-and 4-methoxy7-nitroindolinyl-amino acids as novel, fast caged neurotransmitters. J. Neurosci. Methods 112, 29-42.

Cardin, J. A., Carlén, M., Meletis, K., Knoblich, U., Zhang, F., Deisseroth, K., Tsai, L.-H., and Moore, C. I. (2010). Targeted optogenetic stimulation and recording of neurons in vivo using cell-type-specific expression of channelrhodopsin-2. Nat. Protoc. 5, 247-254.

Carter, M. E., Adamantidis, A., Ohtsu, H., Deisseroth, K., and de Lecea, L. (2009). Sleep homeostasis modulates hypocretin-mediated sleep-towake transitions. J. Neurosci. 29, 10939 .

Chambers, J. J., and Kramer, R. H. (2008). Light-activated ion channels for remote control of neural activity. Methods Cell Biol. 90, 217-232.

Corrie, J. E., DeSantis, A., Katayama, Y., Khodakhah, K., Messenger, J. B., Ogden, D. C., and Trentham, D. R. (1993). Postsynaptic activation at the squid giant synapse by photolytic release of L-glutamate from a "caged" L-glutamate. J. Physiol. (Lond.) 465, 1-8.

Dal Maschio, M., Difato, F., Beltramo, R., Blau, A., Benfenati, F., and Fellin, T. (2010). Simultaneous two-photon imaging and photo-stimulation with structured light illumination. Opt. Express 18, 18720-18731.

Dalva, M. B., and Katz, L. C. (1994). Rearrangements of synaptic connections in visual cortex revealed by laser photostimulation. Science 265, 255-258.

Dalva, M. B., Weliky, M., and Katz, L. C. (1997). Relationships between local synaptic connections and orientation domains in primary visual cortex. Neuron 19, 871-880.

Dan, Y., Alonso, J. M., Usrey, W. M., and Reid, R. C. (1998). Coding of visual information by precisely correlated spikes in the lateral geniculate nucleus. Nat. Neurosci. 1, 501-507.

deCharms, R. C., and Merzenich, M. M. (1996). Primary cortical representation of sounds by the coordination of action-potential timing. Nature 381, 610-613.

Denk, W., Strickler, J. H., and Webb, W. W. (1990). Two-photon laser scanning fluorescence microscopy. Science 248,73 .

Dhawale, A. K., Hagiwara, A., Bhalla, U. S., Murthy, V. N., and Albeanu, D. F.
(2010). Non-redundant odor coding by sister mitral cells revealed by light addressable glomeruli in the mouse. Nat. Neurosci. 13, 1404-1412.

Douglass, A. D., Kraves, S., Deisseroth, K., Schier, A. F., and Engert, F. (2008). Escape behavior elicited by single, channelrhodopsin-2-evoked spikes in zebrafish somatosensory neurons. Curr. Biol. 18, 1133-1137.

Einstein, A. (1905). Über einen die Erzeugung und Verwandlung des Lichtes betreffenden heuristischen Gesichtspunkt. Ann. Phys. 322, 132-148.

Ellis-Davies, G. C. R. (2008). Neurobiology with caged calcium. Chem. Rev. 108, 1603-1613.

Farber, I. C., and Grinvald, A. (1983). Identification of presynaptic neurons by laser photostimulation. Science 222, 1025-1027.

Fedoryak, O. D., Sul, J.-Y., Haydon, P. G., and Ellis-Davies, G. C. R. (2005). Synthesis of a caged glutamate for efficient one- and two-photon photorelease on living cells. Chem. Commun. 29, 3664.

Feng, G., Mellor, R. H., Bernstein, M., Keller-Peck, C., Nguyen, Q. T., Wallace, M., Nerbonne, J. M., Lichtman, J. W., and Sanes, J. R. (2000). Imaging neuronal subsets in transgenic mice expressing multiple spectral variants of GFP. Neuron 28, 41-51.

Fino, E., Araya, R., Peterka, D. S., Salierno, M., Etchenique, R., and Yuste, R. (2009). RuBi-glutamate: two-photon and visible-light photoactivation of neurons and dendritic spines. Front. Neural Circuits 3:2. doi:10.3389/neuro.04.002.2009

Fortin, D. L., Dunn, T. W., Fedorchak, A., Allen, D., Montpetit, R., Banghart, M. R., Trauner, D., Adelman, J. P., and Kramer, R. H. (2011). Optogenetic photochemical control of designer $\mathrm{K}+$ channels in mammalian neurons. J. Neurophysiol. 106, 488-496.

Furuta, T., Wang, S. S. H., Dantzker, J. L., Dore, T. M., Bybee, W. J., Callaway, E. M., Denk, W., and Tsien, R. Y. (1999). Brominated 7-hydroxycoumarin-4ylmethyls: photolabile protecting groups with biologically useful cross-sections for two photon photolysis. Proc. Natl. Acad. Sci. U.S.A. 96, 1193.

Gasparini, S., and Magee, J. C. (2006). State-dependent dendritic computation in hippocampal CA1 pyramidal neurons. J. Neurosci. 26, 2088.

Ghezzi, D., Menegon, A., Pedrocchi, A., Valtorta, F., and Ferrigno, G. (2008). A micro-electrode array device coupled to a laser-based system for the local stimulation of neurons by optical release of glutamate. J. Neurosci. Methods 175, 70-78.

Ghezzi, D., Pedrocchi, A., Menegon, A., Mantero, S., Valtorta, F. and Ferrigno, G. (2007). PhotoMEA: an opto-electronic biosensor for monitoring in vitro neuronal network activity. BioSystems 87, 150-155.

Godwin, D. W., Che, D., O'Malley, D. M., and Zhou, Q. (1997). Photostimulation with caged neurotransmitters using fiber optic lightguides. $J$. Neurosci. Methods 73, 91-106.

Golan, L., Reutsky, I., Farah, N., and Shoham, S. (2009). Design and characteristics of holographic neural photo-stimulation systems. J. Neural Eng. 6, 066004.

Göppert-Mayer, M. (1931). Ueber Elementarakte mit zwei Quantensprüngen. Ann. Phys. 401, 273-294.

Gordon, G. R. J., Iremonger, K. J. Kantevari, S., Ellis-Davies, G. C. R., MacVicar, B. A., and Bains, J. S. (2009). Astrocyte-mediated distributed plasticity at hypothalamic glutamate synapses. Neuron 64 391-403.

Gorostiza, P., and Isacoff, E. (2007). Optical switches and triggers for the manipulation of ion channels and pores. Mol Biosyst 3, 686.

Govorunova, E. G., Spudich, E. N., Lane, C. E., Sineshchekov, O. A., and Spudich, J. L. (2011). New channelrhodopsin with a redshifted spectrum and rapid kinetics from Mesostigma viride. MBio 2. Available at: http://mbio.asm.org/ content/2/3/e00115-11.abstract [accessed September 15, 2011].

Gunaydin, L. A., Yizhar, O., Berndt, A., Sohal, V. S., Deisseroth, K., and Hegemann, P. (2010). Ultrafast optogenetic control. Nat. Neurosci. 13, 387-392.

Gutierrez, R., Simon, S. A., and Nicolelis, M. A. L. (2010). Licking-induced synchrony in the taste-reward circuit improves cue discrimination during learning. J. Neurosci. 30, 287-303.

Han, X., and Boyden, E. S. (2007). Multiple-color optical activation, silencing, and desynchronization of neural activity, with singlespike temporal resolution. PLoS ONE 2, e299. doi:10.1371/journal.pone.0000299

Harvey, C. D., and Svoboda, K. (2007). Locally dynamic synaptic learning rules in pyramidal neuron dendrites. Nature 450, 1195-1200.

Hira, R., Honkura, N., Noguchi, J., Maruyama, Y., Augustine, G. J., Kasai, H., and Matsuzaki, M. (2009). Transcranial optogenetic stimulation for functional mapping of the motor cortex. J. Neurosci. Methods 179, 258-263.

Huber, D., Petreanu, L., Ghitani, N., Ranade, S., Hromádka, T., Mainen, Z., and Svoboda, K. (2008). Sparse optical microstimulation in barrel cortex drives learned behaviour in freely moving mice. Nature 451, 61-64.

Huetz, C., Philibert, B., and Edeline, J.-M. (2009). A spike-timing code for discriminating conspecific vocalizations in the thalamocortical system of anesthetized and awake guinea pigs. J. Neurosci. 29, 334-350.

Ishizuka, T., Kakuda, M., Araki, R., and Yawo, H. (2006). Kinetic evaluation of photosensitivity in genetically engineered neurons expressing green algae light-gated channels. Neurosci. Res. 54, 85-94.

Jerome, J., Foehring, R. C., Armstrong, W. E., Spain, W. J., and Heck, D. H. (2011). Parallel optical control of spatiotemporal neuronal spike activity using high-speed digital light processing. Front. Syst. Neurosci. 5:70. doi:10.3389/fnsys.2011.00070

Kandler, K., Katz, L. C., and Kauer, J. A. (1998). Focal photolysis of caged glutamate produces long-term depression of hippocampal glutamate receptors. Nat. Neurosci. 1, 119-123.

Kantevari, S., Matsuzaki, M., Kanemoto, Y., Kasai, H., and Ellis-Davies, G. C. R. (2010). Two-color, two-photon uncaging of glutamate and GABA. Nat. Methods 7, 123-125.

Kaplan, J. H., Forbush, B. III, and Hoffman, J. F. (1978). Rapid photolytic release of adenosine 5'-triphosphate from a protected analogue: utilization by the Na:K pump of human red blood cell ghosts. Biochemistry 17, 1929-1935.

Katz, L. C., and Dalva, M. B. (1994). Scanning laser photostimulation: a new approach for analyzing brain circuits. J. Neurosci. Methods 54, 205-218.

Kreiter, A. K., and Singer, W. (1996). Stimulus-dependent synchronization of neuronal responses in the visual cortex of the awake macaque monkey. J. Neurosci. 16, 2381-2396.

Kumar, A., Rotter, S., and Aertsen, A. (2010). Spiking activity propagation in neuronal networks: reconciling different perspectives on neural coding. Nat. Rev. Neurosci. 11, 615-627.

Leifer, A. M., Fang-Yen, C., Gershow, M., Alkema, M. J., and Samuel, A. D. T. (2011). Optogenetic manipulation of neural activity in freely moving Caenorhabditis elegans. Nat. Methods 8, 147-152. 
Lester, H. A., Krouse, M. E., Nass, M. M., Wassermann, N. H., and Erlanger, B. F. (1980). A covalently bound photoisomerizable agonist: comparison with reversibly bound agonists at electrophorus electroplaques. J. Gen. Physiol. 75, 207-232.

Lewis, T. L., Mao, T., Svoboda, K., and Arnold, D. B. (2009). Myosindependent targeting of transmembrane proteins to neuronal dendrites. Nat. Neurosci. 12, 568-576.

Li, X., Gutierrez, D. V., Hanson, M. G., Han, J., Mark, M. D., Chiel, H., Hegemann, P., Landmesser, L. T., and Herlitze, S. (2005). Fast noninvasive activation and inhibition of neural and network activity by vertebrate rhodopsin and green algae channelrhodopsin. Proc. Natl. Acad. Sci. U.S.A. 102, 17816.

Liang, C. W., Mohammadi, M., Santos, M. D., Santos, M. D., and Tang, C.-M. (2011). Patterned photostimulation with digital micromirror devices to investigate dendritic integration across branch points. $J$. Vis. Exp. Available at: http://www. ncbi.nlm.nih.gov/pubmed/21403635 [accessed September 15, 2011].

Liewald, J. F., Brauner, M., Stephens, G. J., Bouhours, M., Schultheis, C., Zhen, M., and Gottschalk, A. (2008). Optogenetic analysis of synaptic function. Nat. Methods 5, 895-902.

Lima, S. Q., and Miesenböck, G. (2005). Remote control of behavior through genetically targeted photostimulation of neurons. Cell 121, 141-152.

Lin, J. Y., Lin, M. Z., Steinbach, P., and Tsien, R. Y. (2009). Characterization of engineered channelrhodopsin variants with improved properties and kinetics. Biophys. J. 96, 1803-1814.

Losonczy, A., and Magee, J. C. (2006). Integrative properties of radial oblique dendrites in hippocampal CA1 pyramidal neurons. Neuron 50, 291-307.

Losonczy, A., Makara, J. K., and Magee, J. C. (2008). Compartmentalized dendritic plasticity and input feature storage in neurons. Nature 452, 436-441.

Madisen, L., Zwingman, T. A., Sunkin, S. M., Oh, S. W., Zariwala, H. A., Gu, H., Ng, L. L., Palmiter, R. D., Hawrylycz, M. J., Jones, A. R., Lein, E. S., and Zeng, H. (2010). A robust and high-throughput Cre reporting and characterization system for the whole mouse brain. Nat. Neurosci. 13, 133-140.

Maier, W., Schemm, R., Grewer, C., and Laube, B. (2007). Disruption of interdomain interactions in the glutamate binding pocket affects differentially agonist affinity and efficacy of N-methyl-daspartate receptor activation. J. Biol. Chem. 282, 1863-1872.

Makara, J. K., Losonczy, A., Wen, Q. and Magee, J. C. (2009). Experiencedependent compartmentalized dendritic plasticity in rat hippocampal CA1 pyramidal neurons. Nat. Neurosci. 12, 1485-1487.

Matsubara, N., Billington, A. P., and Hess, G. P. (1992). How fast does an acetylcholine receptor channel open? Laser-pulse photolysis of an inactive precursor of carbamoylcholine in the microsecond time region with $\mathrm{BC} 3 \mathrm{H} 1$ cells. Biochemistry 31, 5507-5514.

Matsui, A., Yoshida, A. C., Kubota, M., Ogawa, M., and Shimogori, T. (2011). Mouse in utero electroporation: controlled spatiotemporal gene transfection. J. Vis. Exp. Available at: http://www. ncbi.nlm.nih.gov/pubmed/21860382 [accessed September 15, 2011].

Matsuzaki, M., Ellis-Davies, G. C., Nemoto, T., Miyashita, Y., Iino, M., and Kasai, H. (2001). Dendritic spine geometry is critical for AMPA receptor expression in hippocampal CA1 pyramidal neurons. Nat. Neurosci. 4, 1086-1092.

Matsuzaki, M., Ellis-Davies, G. C. R., and Kasai, H. (2008). Threedimensional mapping of unitary synaptic connections by twophoton macro photolysis of caged glutamate. J. Neurophysiol. 99, 1535-1544.

Matsuzaki, M., Honkura, N., EllisDavies, G. C. R., and Kasai, H. (2004). Structural basis of longterm potentiation in single dendritic spines. Nature 429, 761-766.

Mohanty, S. K., Reinscheid, R. K., Liu, X., Okamura, N., Krasieva, T. B., and Berns, M. W. (2008). In-depth activation of channelrhodopsin 2sensitized excitable cells with high spatial resolution using two-photon excitation with a near-infrared laser microbeam. Biophys. J. 95, 3916-3926.

Nagel, G. (2002). Channelrhodopsin-1: a light-gated proton channel in green algae. Science 296, 2395-2398.

Nagel, G., Brauner, M., Liewald, J. F., Adeishvili, N., Bamberg, E., and Gottschalk, A. (2005). Light activation of channelrhodopsin-2 in excitable cells of Caenorhabditis elegans triggers rapid behavioral responses. Curr. Biol. 15, 2279-2284.

Nagel, G., Szellas, T., Huhn, W., Kateriya, S., Adeishvili, N., Berthold, P., Ollig, D., Hegemann, P., and Bamberg, E. (2003). Channelrhodopsin-2, a directly light-gated cation-selective membrane channel. Proc. Natl. Acad. Sci. U.S.A. 100, 13940.

Nikolenko, V., Poskanzer, K. E., and Yuste, R. (2007). Two-photon photostimulation and imaging of neura circuits. Nat. Methods 4, 943-950.

Nikolenko, V., Watson, B. O., Araya, R. Woodruff, A., Peterka, D. S., and Yuste, R. (2008). SLM microscopy: scanless two-photon imaging and photostimulation with spatial light modulators. Front. Neural Circuits 2:5. doi:10.3389/neuro.04.005.2008

Nowak, L. G., and Bullier, J. (1998). Axons, but not cell bodies, are activated by electrical stimulation in cortical gray matter. Exp. Brain Res. 118, 477-488.

Papageorgiou, G., and Corrie, J. E. (2000). Effects of aromatic substituents on the photocleavage of 1Acyl-7-nitroindolines. Tetrahedron 56, 8197-8205.

Papageorgiou, G., Ogden, D. C., Barth, A., and Corrie, J. E. T. (1999). Photorelease of carboxylic acids from 1-Acyl-7-nitroindolines in aqueous solution: rapid and efficient photorelease of l-glutamate1. J. Am. Chem. Soc. 121, 6503-6504.

Peticolas, W., Goldsborough, J. P., and Rieckhoff, K. (1963). Double photon excitation in organic crystals. Phys. Rev. Lett. 10, 43-45.

Petreanu, L., Huber, D., Sobczyk, A., and Svoboda, K. (2007). Channelrhodopsin-2-assisted circuit mapping of long-range callosal projections. Nat. Neurosci. 10 , 663-668.

Pettit, D. L., Wang, S. S. H., Gee, K. R., and Augustine, G. J. (1997). Chemical two-photon uncaging: a novel approach to mapping glutamate receptors. Neuron 19, 465-471.

Richardson, R. J., Blundon, J. A., Bayazitov, I. T., and Zakharenko, S. S. (2009). Connectivity patterns revealed by mapping of active inputs on dendrites of thalamorecipient neurons in the auditory cortex. $J$. Neurosci. 29, 6406.

Riehle, A. (1997). Spike synchronization and rate modulation differentially involved in motor cortical function. Science 278, 1950-1953.

Saito, T., and Nakatsuji, N. (2001). Efficient gene transfer into the embryonic mouse brain using in vivo electroporation. Dev. Biol. 240, 237-246.

Salinas, E., and Sejnowski, T. J. (2001). Correlated neuronal activity and the flow of neural information. Nat. Rev. Neurosci. 2, 539-550.

Schroll, C., Riemensperger, T., Bucher, D., Ehmer, J., Völler, T., Erbguth, K., Gerber, B., Hendel, T., Nagel, G., Buchner, E., and Fiala, A. (2006). Light-induced activation of distinct modulatory neurons triggers appetitive or aversive learning in Drosophila larvae. Curr. Biol. 16, 1741-1747.

Shembekar, V. R., Chen, Y., Carpenter, B. K., and Hess, G. P. (2005). A protecting group for carboxylic acids that can be photolyzed by visible light. Biochemistry 44, 7107-7114.

Shepherd, G. M. G., Pologruto, T. A., and Svoboda, K. (2003). Circuit analysis of experience-dependent plasticity in the developing rat barrel cortex. Neuron 38, 277-289.

Shoham, S., O'Connor, D. H., Sarkisov, D. V., and Wang, S. S.-H. (2005). Rapid neurotransmitter uncaging in spatially defined patterns. Nat. Methods 2, 837-843.

Single-Panel DLP Projection System Optics. (2005). Texas Instruments Application Report Discovery DLPA002. Available at: http://focus. ti.com/pdfs/dlpdmd/Discoverydlpa 002.pdf

Steinmetz, P. N., Roy, A., Fitzgerald, P. J., Hsiao, S. S., Johnson, K. O., and Niebur, E. (2000). Attention modulates synchronized neuronal firing in primate somatosensory cortex. Nature 404, 187-190.

Suga, T., Hirano, M., Takayanagi, M., Koshimoto, H., and Watanabe, A. (1998). Restricted photorelease of biologically active molecules near the plasma membrane. Biochem. Biophys. Res. Commun. 253, 423-430.

Szobota, S., Gorostiza, P., Del Bene, F., Wyart, C., Fortin, D. L., Kolstad, K. D., Tulyathan, O., Volgraf, M. Numano, R., Aaron, H. L., Scott, E. K., Kramer, R. H., Flannery, J., Baier, H., Trauner, D., and Isacoff, E. Y. (2007). Remote control of neuronal activity with a light-gated glutamate receptor. Neuron 54, 535-545.

Tønnesen, J., Sørensen, A. T., Deisseroth, K., Lundberg, C., and Kokaia, M. (2009). Optogenetic control of epileptiform activity. Proc. Natl. Acad. Sci. U.S.A. 106, 12162-12167.

Trigo, F. F., Corrie, J. E. T., and Ogden, D. (2009). Laser photolysis of caged compounds at $405 \mathrm{~nm}$ : photochemical advantages, localisation, phototoxicity and methods for calibration. J. Neurosci. Methods 180, 9-21.

Vaadia, E., Haalman, I., Abeles, M., Bergman, H., Prut, Y., Slovin, H., and Aertsen, A. (1995). Dynamics of neuronal interactions in monkey cortex in relation to behavioural events. Nature 373, 515-518.

Volgraf, M., Gorostiza, P., Numano, R., Kramer, R. H., Isacoff, E. Y., and Trauner, D. (2006). Allosteric control of an ionotropic glutamate receptor with an optical switch. Nat. Chem. Biol. 2, 47-52. 
Volgraf, M., Gorostiza, P., Szobota, S., Max, R., Isacoff, E. Y., and Trauner, D. (2007). Reversibly caged glutamate: a photochromic agonist of ionotropic glutamate receptors. J. Am. Chem. Soc. 129, 260-261.

Wang, H., Peca, J., Matsuzaki, M., Matsuzaki, K., Noguchi, J., Qiu, L., Wang, D., Zhang, F., Boyden, E., Deisseroth, K., Kasai, H., Hall, W. C., Feng, G., and Augustine, G. J. (2007a). High-speed mapping of synaptic connectivity using photostimulation in channelrhodopsin-2 transgenic mice. Proc. Natl. Acad. Sci. U.S.A. 104, 8143 .

Wang, S., Szobota, S., Wang, Y., Volgraf, M., Liu, Z., Sun, C., Trauner, D., Isacoff, E. Y., and Zhang, X. (2007b). All optical interface for parallel, remote, and spatiotemporal control of neuronal activity. Nano Lett. 7, 3859-3863.

Wang, S. S. H., Khiroug, L., and Augustine, G. J. (2000). Quantification of spread of cerebellar long-term depression with chemical twophoton uncaging of glutamate. Proc. Natl. Acad. Sci. U.S.A. 97, 8635.

Wilcox, M., Viola, R., Johnson, K., Billington, A., Carpenter, B., McCray, J., Guzikowski, A., and Hess, G. (1990). Synthesis of photolabile precursors of amino acid neurotransmitters. J. Org. Chem. 55, 1585-1589.

Zahid, M., Vélez-Fort, M., Papagiakoumou, E., Ventalon, C., Angulo, M. C., and Emiliani, V. (2010) Holographic photolysis for multiple cell stimulation in mouse hippocampal slices. PLoS ONE 5, e9431. doi:10.1371/journal.pone.0009431

Zemelman, B. V., Lee, G. A., Ng, M., and Miesenböck, G. (2002). Selective photostimulation of genetically chARGed neurons. Neuron 33, 15-22.

Zhang, F., Prigge, M., Beyrière, F., Tsunoda, S. P., Mattis, J., Yizhar, O., Hegemann, P., and Deisseroth, K. (2008a).
Red-shifted optogenetic excitation: a tool for fast neural control derived from Volvox carteri. Nat. Neurosci. 11,631 .

Zhang, Y. P., Holbro, N., and Oertner, T. G. (2008b). Optical induction of plasticity at single synapses reveals input-specific accumulation of alphaCaMKII. Proc. Natl. Acad. Sci. U.S.A. 105, 12039.

Zhu, P., Narita, Y., Bundschuh, S. T., Fajardo, O., Schärer, Y. P. Z., Chattopadhyaya, B., Bouldoires, E. A., Stepien, A. E., Deisseroth, K., Arber, S., Sprengel, R., Rijli, F. M., and Friedrich, R. W. (2009). Optogenetic dissection of neuronal circuits in zebrafish using viral gene transfer and the Tet system. Front. Neural Circuits 3:21. doi:10.3389/neuro.04.021.2009

Zito, K., Scheuss, V., Knott, G., Hill, T., and Svoboda, K. (2009). Rapid functional maturation of nascent dendritic spines. Neuron 61, 247-258.
Conflict of Interest Statement: The authors declare that the research was conducted in the absence of any commercial or financial relationships that could be construed as a potential conflict of interest.

Received: 21 September 2011; accepted: 01 November 2011; published online: 07 December 2011.

Citation: Jerome J and Heck DH (2011)

The age of enlightenment: evolving opportunities in brain research through optical manipulation of neuronal activity. Front. Syst. Neurosci. 5:95. doi: 10.3389/fnsys.2011.00095

Copyright (C) 2011 Jerome and Heck. This is an open-access article subject to a nonexclusive license between the authors and Frontiers Media SA, which permits use, distribution and reproduction in other forums, provided the original authors and source are credited and other Frontiers conditions are complied with. 